\title{
Influence of shear plugging in the energy absorbed by thin carbon-fibre laminates subjected to high-velocity impacts
}

\author{
Brenda L. Buitrago ${ }^{\mathrm{a}}$, Shirley K. García-Castillo ${ }^{\mathrm{b}}$, Enrique Barbero ${ }^{\mathrm{b}, *}$ \\ ${ }^{a}$ Department of Industrial Technology, University Simon Bolivar, Valle de Sartenejas, Caracas, Venezuela \\ ${ }^{\mathrm{b}}$ Department of Continuum Mechanics and Structural Analysis, University Carlos III of Madrid, Leganés, Spain ${ }^{1}$
}

Keywords:

A. Carbon fibre

A. Laminates

B. Impact behaviou

C. Analytical modelling

Shear plugging

\begin{abstract}
A B S T R A C T
This work examines the energy-absorption process in thin woven laminates made from carbon fibres, with the aim of analysing the energy employed in the formation of a shear plug. This study was conducted with a simplified model which considered five energy-absorption mechanisms. The model was validated with experimental tests and numerical simulations, with regard to the residual velocity of the projectile and perforation velocity. The model makes it possible to evaluate the influence of the shear plugging in laminates of different thickness. It has been demonstrated that this energy-absorption mechanism needs to be considered in the analysis. The main energy-absorption mechanisms for impact at low velocity (i.e. below the perforation velocity) are related to the elastic deformation of fibres and shear plugging, whereas when a higher impact velocity is considered (i.e. above the perforation velocity) such mechanisms are related to the acceleration field of the laminate and the shear plugging.
\end{abstract}

\section{Introduction}

Despite that the response of composite laminates subjected to high-velocity impact has been extensively studied (see e.g. reviews [1-4]), knowledge of the phenomenon of perforation of a laminate struck by a low-mass projectile remains incomplete.

A detailed modelling of the response of a laminate subjected to high-velocity impact is very difficult due to the complexity of the perforation process. Analytical models can be useful to study this process by providing a sufficiently accurate solution with a lower computational cost than numerical methods and by describing the physical behaviour of the laminate. There are countless simplified analytical models for ballistic impacts (e.g. see [3] for a review of these models). Many of these models have focused only on estimating the perforation velocity $[5,6]$ whereas less information is available related to the energy absorbed by the different failure mechanisms.

The energy of the projectile is absorbed by the laminate through several mechanisms, including the energy converted into the kinetic energy of a moving portion of the laminate (laminate acceleration), damage generation (fibre and matrix failure, delamination, etc.), formation of a shear plug, friction, heating, etc. [7,8]. The relative importance of each mechanism depends on the material, plate thickness, and laminate configuration, as well as on the pro-

\footnotetext{
* Corresponding author.

E-mail address: ebarbero@ing.uc3m.es (E. Barbero).

${ }^{1}$ http://www.uc3m.es/mma.
}

jectile geometry and size $[9,10]$. Also the relevance of each mechanism could change with impact velocity. Usually, for thin laminates, friction and heating are negligible [7]. Shear-plug formation is not observed for thin glass-reinforced composites [8]. Such mechanisms as matrix or delamination failure are less relevant than fibre failure, especially in thin glass-reinforced laminates [7,8,11], for which the energy absorbed by fibre deformation and failure, and laminate acceleration, are the main mechanisms $[7,8,11]$. In thick glass-reinforced laminates, delamination and matrix-crushing mechanisms could be a relevant energy-absorption mechanism. Wen et al. [12] found that in woven glass-reinforced plates $3.25 \mathrm{~mm}$ thick impacted by hemispherical- or conical-ended projectiles the main mechanisms are delamination, matrix crushing, and fibre failure, whereas in flat-ended projectiles, fibre shearing is also notable. Mines et al. [13] also found that shear stress can appear in glass laminates over $4 \mathrm{~mm}$ in thicknesses even with hemispherical projectiles.

The brittle nature of carbon-reinforced laminates implies that the energy-absorption mechanisms differ with respect to glassreinforced laminates. The formation of a shear plug is reported in CFRP woven laminates, even in relatively thin plates [14]. Lee and Sun [15] showed that the main energy-absorption mechanisms are delamination and shear plugging in CFRP tape laminates for thicknesses of 2 and $4 \mathrm{~mm}$ and impact velocities up to $91 \mathrm{~m} / \mathrm{s}$, considering flat-ended projectiles. Tape composites undergo extensive damage by delamination after impact, this mechanism being less relevant in woven laminates $[8,14,16]$. Nevertheless, some authors affirm that there are no differences in energy-absorption capabilities 
between cross-ply tape and woven laminates, especially for higherimpact velocities $[17,18]$. According to Hazell and Appleby-Thomas [18], tape laminates at lower impact energies behave better than woven laminates under ballistic impact. Several authors have studied the impact behaviour of CFRP woven laminates [9,14,19-22], but much less information is available in relation to the importance of each energy-absorption mechanism and the influence of the impact energy in each mechanism. Naik and Shrirao [20] showed that for a CFRP woven laminate impacted by flat-ended projectile slightly over perforation velocity the main mechanism is the energy of the moving portion of the laminate, the energy absorbed by shear plugging being less relevant. Goldsmith et al. [19] affirmed that in a $2.5 \mathrm{~mm}$ CFRP woven laminate the main energy-absorption mechanism at perforation velocity is the failure of fibres and friction. As can be seen, contradictory results appear in the literature for the relevance of shear plugging in the perforation process of very thin (below $2 \mathrm{~mm}$ ) CFRP woven laminates subjected to the impact of spherical projectiles.

The objective of the present work is to evaluate the influence of shear-plugging mechanism on the absorption of the energy of the projectile, in a thin CFRP woven laminate subjected to high-velocity impact. Concomitantly, the influence of impact energy in the energy-absorption mechanisms was analysed. An analytical model, based on energy consideration was applied to study this problem. This model is based on the one proposed by García-Castillo et al. $[7,23]$, initially developed for GFRP woven laminates. The model applied in this work incorporates an energy-absorption mechanism due to shear plugging.

\section{Analytical model}

The model, initially developed for GFRP woven laminates, is based on energy-conservation laws. As in the proposals of Morye et al. [11] and Naik et al. [8,20,24], the model considers several energy-absorption mechanisms: energy absorbed by fibres $\left(E_{F B}\right)$, energy absorbed in terms of acceleration field within the laminate $\left(E_{K L}\right)$; energy absorbed by delamination $\left(E_{D L}\right)$, and matrix cracking $\left(E_{M C}\right)$.

In the development of the model, the energy absorbed by friction between the laminate and the projectile, and the heating generated were not included because the laminate is considered very thin.

In this work, the model was modified by adding a new mechanism, the energy absorbed by the formation of a plug due to shear stress $\left(E_{S P}\right)$, and thus the total absorbed energy can be calculated by:

$E_{A B}(t)=E_{F B}(t)+E_{K L}(t)+E_{D L}(t)+E_{M C}(t)+E_{S P}(t)$

In this paper, the energy-absorption mechanisms included in the model of Garcia-Castillo et al. are briefly described. A detailed description of the expressions for each mechanism can be found in García-Castillo et al. [7,25]. Here, only the mechanism of energyabsorption due to shear plugging is explained in depth.

\subsubsection{Energy absorbed by fibres}

When a laminate is subjected to high-velocity impact, it is possible to identify two zones affected by the impact. The first zone is located below of projectile, and this portion of laminate offers resistive force against penetration of the projectile. This model assumes that in this region the fibres will fail. Meanwhile, the second one is the region located between the projectile diameter and the distance covered by the transversal waves. This model assumes that in this zone no failure occurs and the fibres are elastically deformed.
In woven laminates, the fibres are grouped in assemblies called yarns, composed of several individual filaments. In this model, the failure is assumed to occur only in the yarns directly below the projectile, which offer resistive force against the penetration of the projectile. The maximum-strain criterion is assumed for fibre failure.

The energy absorbed by fibre failure is calculated by assuming that the projectile diameter is smaller than the width of the yarn, so that the impact occurs only on one yarn.

The fibres deformed elastically during impact lie within the region affected by the transversal stress wave generated by the impact. This region is localized between the projectile diameter and the distance covered by the transversal waves. The strain is assumed to be a linear function of the radial position, from the impact point to the distance covered by the transversal wave, so that the fibres close to the impact point are subject to a deformation equal to the failure strain, whereas the fibres farther away from the impact point show a strain equal to zero.

\subsubsection{Energy absorbed by laminate acceleration}

Due to the impact a portion of the laminate is accelerated. The zone accelerated is equal to the region covered by the transversal wave. The model assumes that the velocity of this region is the same as that of the projectile. Since the laminate is considered thin, this model assumes a constant velocity through the laminate thickness.

\subsubsection{Energy absorbed by delamination}

In this model, the energy absorbed due to damage by delamination is assumed to be a function of the distance covered by transversal wave on the laminate. In experimental tests, the area contributing this mechanism was approximately circular. The damage due to delamination is related to the critical dynamicstrain energy-release rate in mode II.

\subsubsection{Energy absorbed by matrix cracking}

This energy is modelled in a way similar to the energy absorbed due to delamination. Also the area that contributes to this mechanism is approximately equal to a circle. The damage due to matrix cracking is related to the energy absorbed by matrix cracking per unit volume, this being a material property.

\subsubsection{Energy absorbed by shear plugging}

When a CFRP woven laminate is subjected to high-velocity impact, the shear stress through the thickness in the laminate near projectile periphery rises. If this stress exceeds shear-plugging strength, then failure occurs and a shear plug is formed.

In this model the energy absorbed by the formation of a shear plug of a diameter equal to the projectile diameter and a differential length is calculated. It is assumed that this length is equal to the distance covered by the projectile in a differential time $(d w)$. Also the shear-plugging strength and the area over which the shear stress is applied are included in the expression. Thus, the energy absorbed during a differential increment of time can be estimated by the equation:

$d E_{S P}=d w \cdot S_{S P} \cdot \pi \cdot \varphi \cdot e$

where $d E_{S P}$ is the energy absorbed by the formation of shear plug during an increment of time $(d t), S_{S P}$ is the out-of-plane shear strength, $e$ is the laminate thickness and, $\varphi$ is the projectile diameter. 
If Eq. (2) is divided by the time increment ( $d t)$ and is integrated, given the energy absorbed by the formation of the shear plug at each instant in time, then:

$E_{S P}=\int_{0}^{t} v(t) \cdot S_{S P} \cdot \pi \cdot \varphi \cdot e \cdot d t$

where $v(t)$ is the projectile velocity.

\subsection{Model resolution}

According to the energy-conservation principle over the time interval $\left(t_{0}, t\right)$ :

$E_{0}=\frac{1}{2} \cdot m_{p} \cdot v_{0}^{2}=E_{T}(t)=\frac{1}{2} \cdot m_{p} \cdot v^{2}(t)+E_{A B}(t)$

where $E_{0}$ is the impact energy, $v_{0}$ is the impact velocity, $m_{p}$ the mass of projectile, and $E_{T}(t)$ is the total energy at time instant $t$.

From Eqs. (1), (3), and (4) and the expressions for the absorption-energy mechanisms of fibre failure, fibre deformation, laminate acceleration, matrix cracking, and delamination described in Ref. [21], the following differential equation can be derived:

$$
\begin{aligned}
v(t) & \cdot\left[m_{p}+\pi \cdot \rho \cdot e \cdot v_{T}^{2} \cdot t^{2}\right] \cdot \frac{d v(t)}{d t}+\pi \cdot \rho \cdot e \cdot v_{T}^{2} \cdot t \cdot v^{2}(t) \\
& +h(t) \cdot v(t)=g(t)
\end{aligned}
$$

where $\rho$ is the laminate density, $v_{T}$ the velocity of the transversal wave generated by the impact on the laminate and, $h(t)$ and $g(t)$ are known functions, defined as:

$$
\begin{aligned}
h(t)= & \frac{\varepsilon_{r}^{2} \cdot B^{2} \cdot E}{2 \cdot \ln b} \cdot\left[1-\left(\frac{9}{10}\right)^{\left(4 \cdot v_{L} \cdot t / B\right)}\right]+S_{S P} \cdot \pi \cdot \varphi \cdot e \\
g(t)= & -\left[\left(\frac{E \cdot e \cdot \varepsilon_{r}^{2}}{48} \cdot \frac{88 \cdot v_{T}^{3} \cdot t^{3}-44 \cdot \varphi \cdot v_{T}^{2} \cdot t^{2}-22 \cdot \varphi^{2} \cdot v_{T} \cdot t+5 \cdot \varphi^{3}}{\left(\varphi-2 \cdot v_{T} \cdot t\right)^{2}}\right)\right. \\
& \left.+2 \cdot\left(G_{I I C D}+E_{M T} \cdot e\right) \cdot v_{T} \cdot t\right] \cdot \pi \cdot v_{T}
\end{aligned}
$$

where $B$ is the yarn width, $E$ is the Young's modulus, $v_{L}$ is the velocity of the longitudinal wave generated by the impact on the laminate, $E_{M T}$ is the energy absorbed by matrix cracking per unit volume, $G_{I I C D}$ is the critical dynamic-strain energy-release rate in mode II and, $\varepsilon_{r}$ is the failure strain.

The integration of Eq. (5) was finished either when there was perforation or when the projectile stopped. The condition for perforation is defined as:

$t=t_{c}, w\left(t_{c}\right)=e, v\left(t_{c}\right)=v_{R}$ then the absorbed energy is equal to $E_{0}-\frac{1}{2} \cdot m_{p} \cdot v_{R}^{2}$.

And the condition for projectile detention is:

$t=t_{c}, v\left(t_{c}\right)=0$, so that the absorbed energy is equal to $E_{0}$ :

where $v_{R}$ is the residual velocity of projectile, $t_{c}$ is the contact time between the projectile and laminate, and $w\left(t_{c}\right)$ is the projectile displacement at $t_{c}$.

\section{Model validation}

To validate the model, the numerical simulations as well as the experimental tests were performed. The residual velocity of the projectile after perforation was used as the parameter for the model validation. A broad range of impact velocities were analysed, from velocities below the perforation velocity, to velocities much higher than the perforation velocity. Also, the perforation velocity estimated by the model was compared with those calculated by the numerical simulation and with the experimental results.

\subsection{Experimental test}

Experimental high-velocity-impact tests were conducted to validate the analytical model. Made of carbon fibre/epoxy AS4/8552 woven laminate $2 \mathrm{~mm}$ in thickness, the specimens used were square, measuring $120 \times 120 \mathrm{~mm}^{2}$. The specimens were impacted by spherical steel projectiles $7.5 \mathrm{~mm}$ in diameter, and $1.725 \mathrm{~g}$, at impact velocities from $45 \mathrm{~m} / \mathrm{s}$ up to $560 \mathrm{~m} / \mathrm{s}$ by a stage gas gun. The properties of the laminate were taken from the literature [14].

It was not possible to measure the ballistic limit directly from the experimental tests because there is an impact-velocity interval in which the structure may or may not be entirely perforated; in addition, the impact velocity of the projectile from the gas gun cannot be totally controlled. Therefore, this velocity is often defined in terms of probability as $v_{50}$, meaning that there is a $50 \%$ of probability of perforation [26]. This approach requires a great number of tests around this velocity. In the present work the experimental perforation velocity was estimated, using a least-square method, by fitting the expression shown in the following equation proposed by Lambert and Jonas [27].

$$
v_{r}= \begin{cases}0, & 0 \leq v_{i} \leq v_{p} \\ A \cdot\left(v_{0}^{B}-v_{p}^{B}\right)^{1 / B}, & v_{i}>v_{p}\end{cases}
$$

where $v_{p}$ the perforation velocity, and $A, B$ are fitting parameters. In this work the estimated values for $A$ and $B$ are 1 and 2, with a $R^{2}$ equal to 0.98309 . With this result, Eq. (8) has a physical meaning; it is equivalent to that found assuming the conservation of momentum and energy during the perforation process with zero fragment ejected from the laminate [28].

\subsection{Numerical simulation}

The numerical model reproduces the geometry of the specimens and the impact conditions tested experimentally. A quarter model was applied due to the symmetry of both the projectile and laminate. The model was implemented in Abaqus/Explicit, and 4-node shell elements with reduced integration (S4R in ABAQUS), were used to mesh the laminate, plus three-dimensional 8-node hexahedral elements (C3D8R in ABAQUS) to mesh the projectile. The projectile was meshed using 3800 elements and the laminate with 5439 elements. Clamped boundary conditions were imposed to the external boundary of the laminates, and an initial velocity was imposed on the projectile in order to reproduce the experimental tests.

As no plastic deformation was found experimentally in the projectile, linear elastic behaviour was used for the steel projectile. The laminate was modelled as linear elastic up to failure. A failure criterion and a procedure to degrade mechanical properties after failure were used to define the anisotropic mechanical behaviour. The model applied for damage initiation and evolution implemented in Abaqus/Explicit was based on the Hashin failure criteria [29] for the initiation and fracture energies for damage evolution.

Fig. 1 shows the perforation process of the laminate. As can be seen, the damage was located in a small area around the impact point.

Also, the stress did not reach the edges of the laminate during the perforation process, validating the design of the geometry of the specimens used in the experimental tests.

\subsection{Residual-velocity comparison}

A good correlation between the residual velocities estimated from the analytical model and the results from experimental tests and from the numerical model was found, as can be seen in Fig. 2 . The numerical model slightly underestimates the residual velocity 

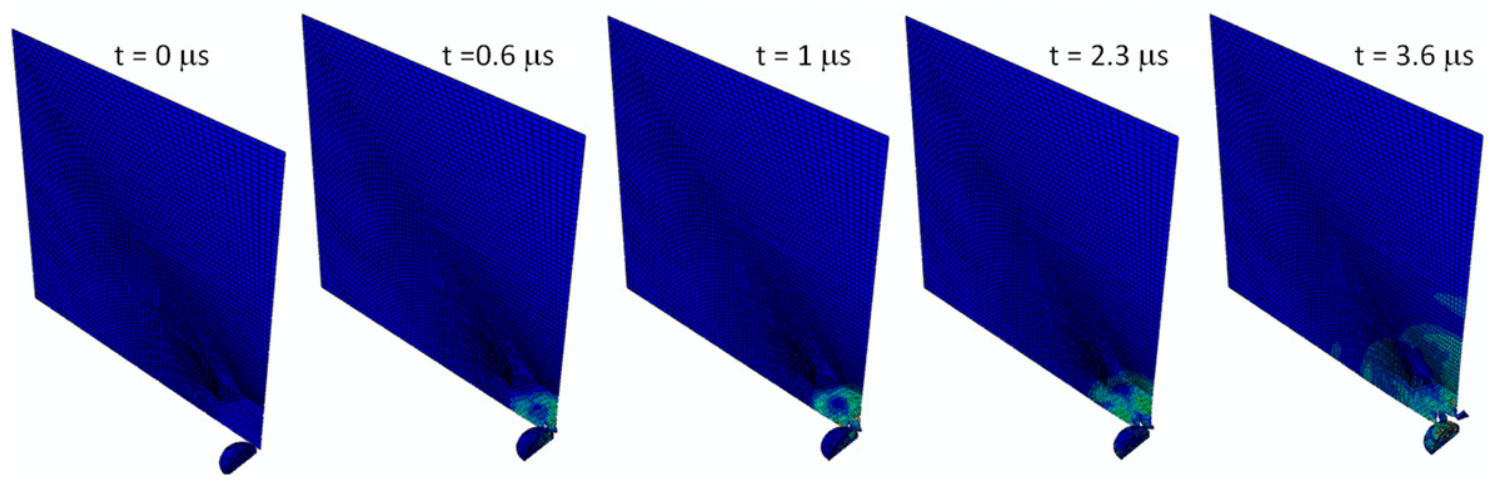

Fig. 1. Time course of the impact process at an impact velocity of $178 \mathrm{~m} / \mathrm{s}$.

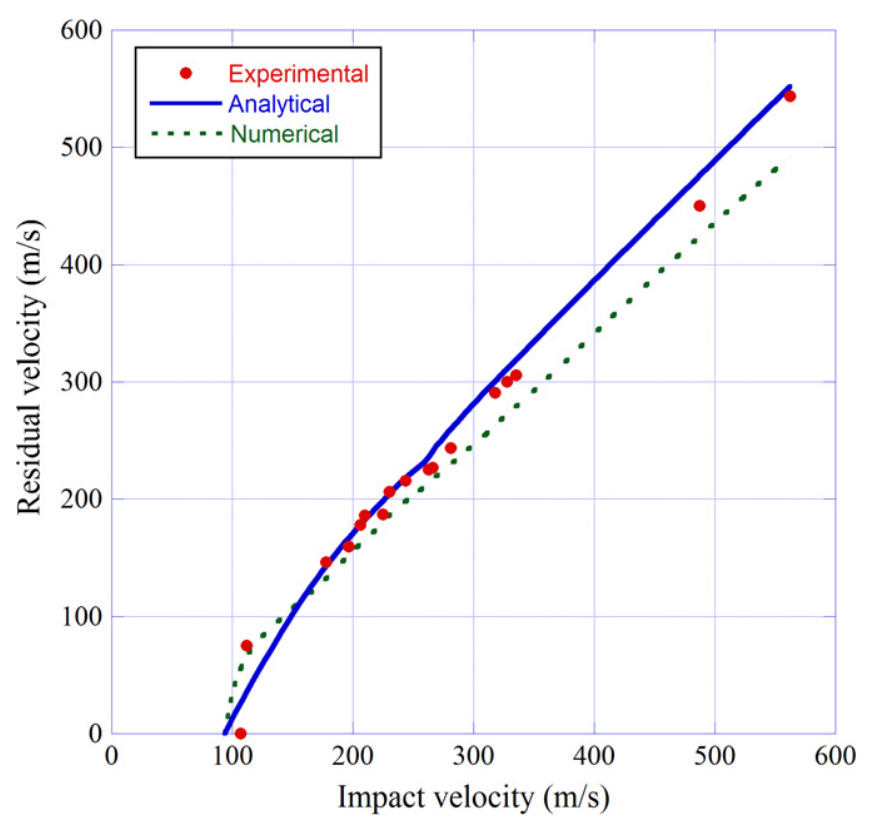

Fig. 2. Residual velocity vs. impact velocity for AS4/8552 woven laminate.

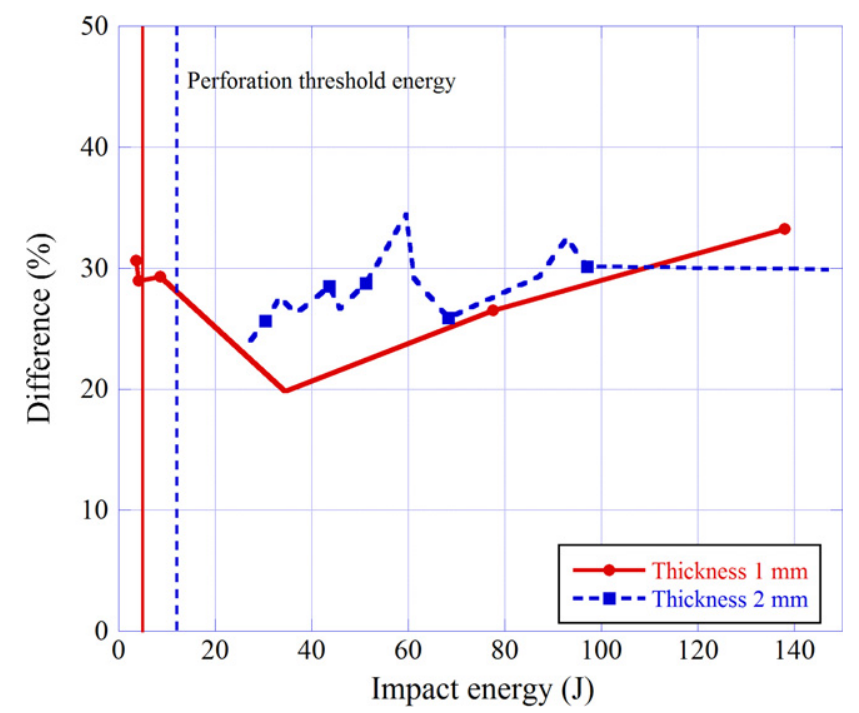

Fig. 3. Difference between the energy absorbed with and without the mechanism of shear plugging for AS4/8552 woven laminate. with regard to the experimental test, while the analytical model slightly overestimates the residual velocity. For example, for an impact velocity of $281 \mathrm{~m} / \mathrm{s}$ the proposed model predicts a residual velocity of $263 \mathrm{~m} / \mathrm{s}$ while the numerical model predicts a residual velocity of $230 \mathrm{~m} / \mathrm{s}$. From the experimental tests the residual velocity measured was $244 \mathrm{~m} / \mathrm{s}, 7 \%$ lower than estimated by the analytical model, and $6 \%$ higher than estimated by the numerical model. Therefore, the differences between the numerical model and the experimental test were similar to those found between the analytical model and the experimental results.

Also, a good result was found in the perforation velocity estimated by the proposed model. The perforation velocity calculated experimentally was equal to $100.2 \pm 3 \mathrm{~m} / \mathrm{s}$, whereas the analytical one was $109 \mathrm{~m} / \mathrm{s}$ (9\% higher) and the numerical one $103.8 \mathrm{~m} / \mathrm{s}$ (4\% higher).

Therefore, the analytical model enables an accurate estimate of the residual velocity and the ballistic limit for thin CFRP woven laminate. Also, the formulation of the model enables the absorbed energy for each energy-absorption mechanism, and hence the total energy absorbed by the laminate.

\section{Results}

\subsection{Effect of the energy absorbed by shear plugging}

For an evaluation the relevance of shear plugging as an energy-absorption mechanism in CFRP woven laminates subjected to high-velocity impacts, the model was applied twice, i.e. with and without this mechanism. Two thicknesses were considered, i.e. 1 and $2 \mathrm{~mm}$, because the proposed model was validated for $2 \mathrm{~mm}$ of thickness.

Fig. 3 shows the difference in percentage between the total energy absorbed for the two thicknesses studied as a function of the impact energy.

The vertical line corresponds to the perforation-threshold energy, which is the minimum impact energy at which the laminate is perforated.

For both thicknesses, the difference in the absorbed energy calculated with an analytical model that considers the shear plugging and those with the same model, but not considering this mechanism, was more and less 30\% for any impact energy. Therefore, it is necessary to consider the energy-absorption mechanism of shear plugging to analyse the behaviour of woven CFRP subjected to high-velocity impacts.

Fig. 4 shows the energy absorbed by each mechanism and the total energy absorbed for two thicknesses: $1.0 \mathrm{~mm}$ and $2.0 \mathrm{~mm}$. For both cases, the energy absorbed by the elastic deformation of fibres, the laminate acceleration, the delamination, the matrix cracking, the shear plugging, and the total energy reached the 

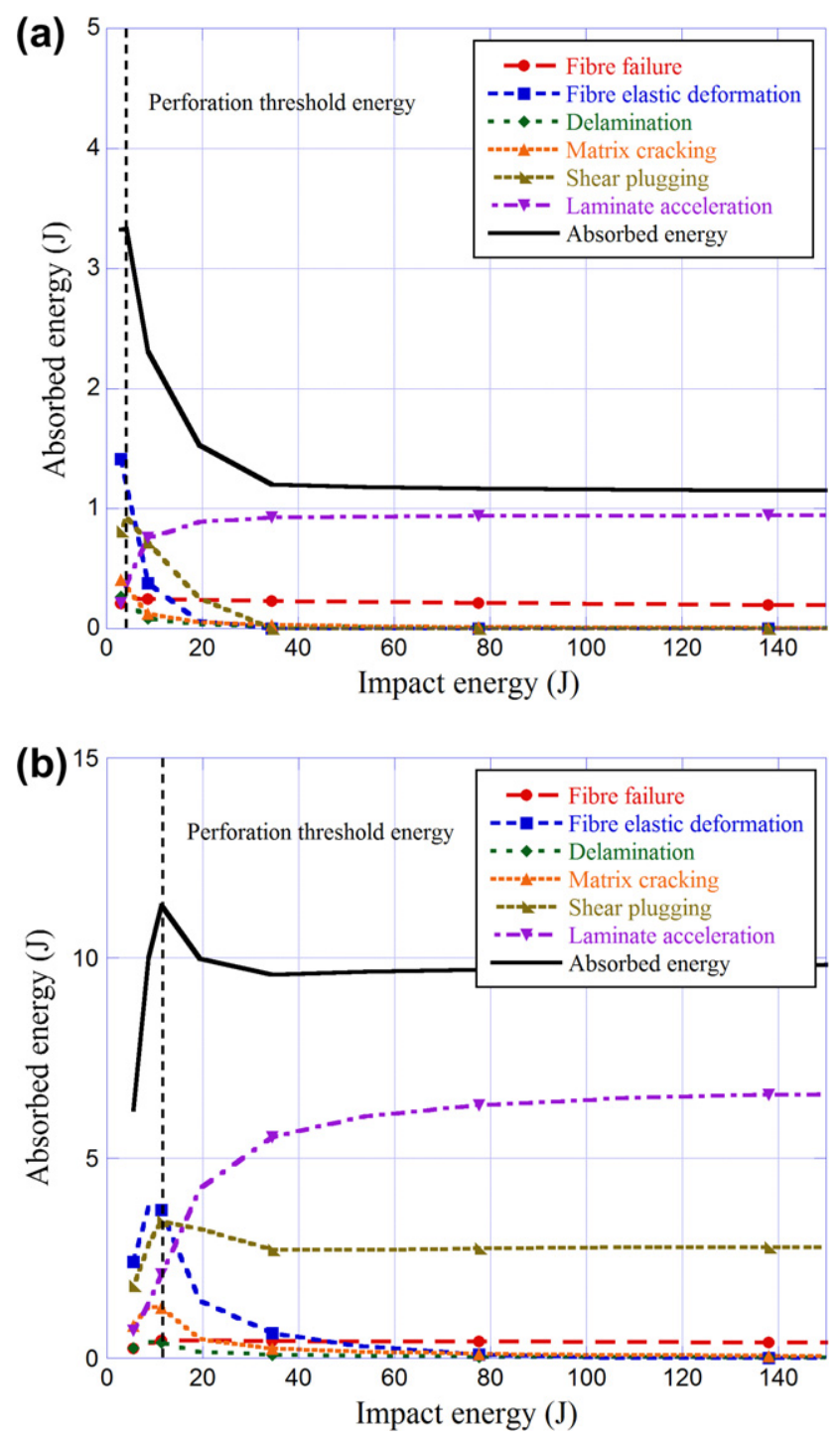

Fig. 4. Absorbed energy vs. impact energy for AS4/8552 woven laminate: (a) thickness $1 \mathrm{~mm}$ and (b) thickness $2 \mathrm{~mm}$.

maximum value, when the impact energy was equal to the perforation-threshold energy.

For impact energy above the perforation-threshold energy, the main energy-absorption mechanism was laminate acceleration; this mechanism is the most relevant one, because this energy is proportional to the square of the impact velocity. Fig. 4 shows that the energy absorbed by the laminate acceleration of $2 \mathrm{~mm}$ in thickness was sixfold the energy absorbed by the laminate of $1 \mathrm{~mm}$.

The energy absorbed by the shear plugging reached the maximum value around the perforation-threshold energy and afterwards decreased asymptotically, this behaviour being observed for the two thicknesses studied. This mechanism depends directly on the contact time between the laminate and the projectile (Eq. (4)), and at the perforation-threshold energy the contact time is the highest. For impact energies slightly over the perforationthreshold energy the shear plugging could be the main mechanism, for the 2-mm-thick laminate. For other impact energies, this was the second most relevant mechanism. For high-impact energies the percentage of energy absorbed by shear plugging was around $30 \%$ of the total absorbed energy. By contrast, for these impact energies this mechanism was almost nil for the 1-mm-thick laminate. However, below the perforation-threshold energy the shear plugging mechanism absorbed more than $20 \%$ of the total absorbed energy for both thicknesses.

The energy absorbed by fibre failure was constant for both thicknesses, being less than $5 \%$ of the total energy for the $2-\mathrm{mm}$ thick laminate, and less than $20 \%$ for the other thickness.

The energy absorbed by the fibre elastic deformation diminished with impact energy above the perforation-threshold energy, approaching a value of zero. For the lowest impact energy analysed in this work, this mechanism absorbed around $40 \%$ of the total energy.

The energy absorbed by delamination and matrix cracking also diminished with the impact energy, because these mechanisms are proportional to the distance covered by the transversal waves, and this distance shortens as the impact energy augments. These mechanisms are negligible at high impact energy. These results agree with those from c-scan images of the impacted specimens in the experimental tests, where the observed damage diminishes as the impact energy increases, being low at high impact energies.

The behaviour described for the energy absorbed by the acceleration laminate, the fibre failure, the fibre elastic deformation, the matrix cracking, and the delamination are similar to GFRP woven laminates. By contrast, the contribution of the shear-plugging mechanism is completely different, due to the low out-of-plane shear strength of the CFRP woven laminates.

\subsection{Effect of laminate thickness in the energy absorbed by shear plugging}

The variation in the energy-absorption mechanism was studied during the perforation of the laminate, by selecting impact energy that causes the complete perforation $(77 \mathrm{~J})$.

Figs. 5 and 6 present the energy absorbed by each absorption mechanism as a function of contact time for two laminate thicknesses: 1 and $2 \mathrm{~mm}$. All mechanisms increase with the contact time.

From the first instant in time after the impact the energy absorbed by the laminate, acceleration very quickly increased. At the end of the perforation, some $65 \%$ of the total energy was absorbed by this mechanism in the 2 -mm-thick laminate, while the 1-mm-thick laminate absorbed $81 \%$.

Fibre failure increased more slowly with time than did the previous mechanism. At the end of the perforation process the energy absorbed by this mechanism was equal to $4 \%$ of total absorbed energy in the 2 -mm-thick laminate and $17 \%$ in the 1 -mm-thick laminate.

The energy absorbed by fibres elastic deformation, delamination, and matrix cracking can be neglected. Naik and Shrirao [15] also affirm that, for a woven laminate of T300 carbon/epoxy impacted by a flat projectile; these three mechanisms are not relevant.

The main difference in the behaviour of both thicknesses concerns the energy absorbed by shear plugging. This mechanism was not observed for the $1 \mathrm{~mm}$ thick laminate, because this laminate behaves somewhat like a membrane. However, for the 2-mmthick laminate, this mechanism contributes to reduce the kinetic energy of the projectile. At the instant of perforation the energy absorbed by this mechanism was equal to $28 \%$ of the total absorbed energy.

The previous results demonstrate the necessity of studying the energy absorbed by shear plugging for thin laminates of different thicknesses and different impact energies.

To analyse the variation in the energy absorbed by shear plugging with the displacement of projectile, several levels of impact energy were selected and four laminates of different thickness were studied $(0.5 \mathrm{~mm}, 1.0 \mathrm{~mm}, 1.5 \mathrm{~mm}$ and $2 \mathrm{~mm}$ ). First, an impact energy that did not result in the perforation for all thicknesses 


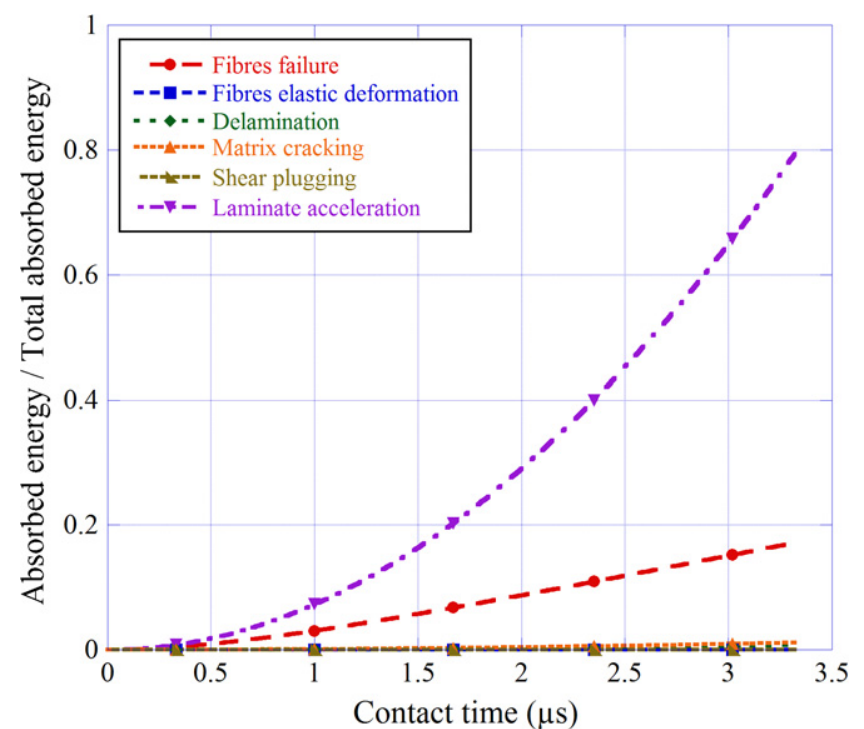

Fig. 5. Variation in absorbed energy during the perforation of an AS4/8552 woven laminate (1 $\mathrm{mm}$ thick) at impact energy of $77 \mathrm{~J}$.

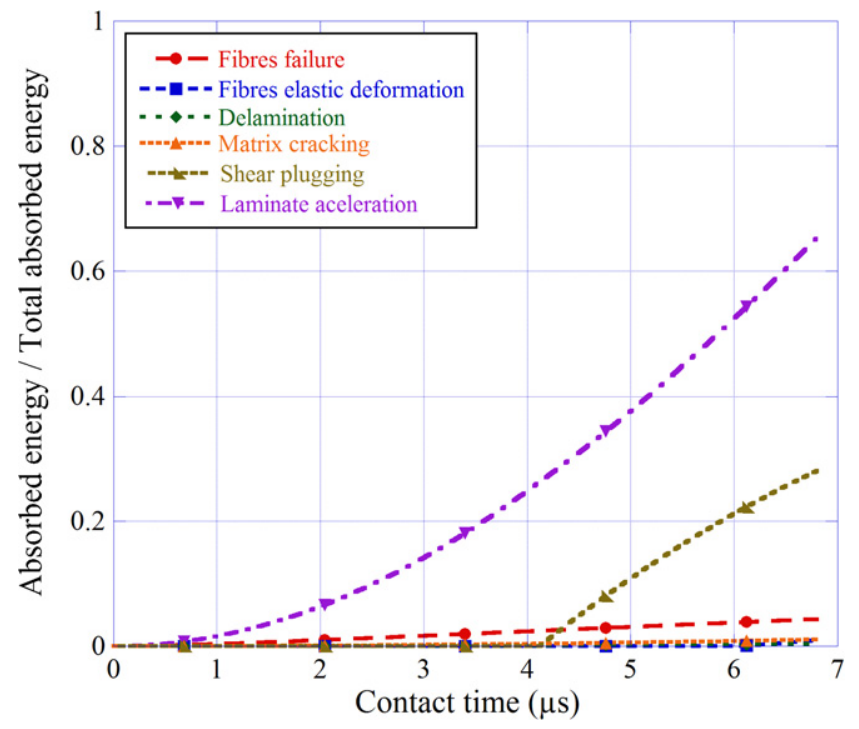

Fig. 6. Variation in the absorbed energy during the perforation of an AS4/8552 woven laminate ( $2 \mathrm{~mm}$ thick) at impact energy of $77 \mathrm{~J}$.

considered in this study $(0.77 \mathrm{~J})$, second an impact energy equal to perforation-threshold energy of each laminate and finally an impact energy that resulted in perforation of all laminates $(77 \mathrm{~J})$.

Figs. 7-9 show the relationship between the energy absorbed by shear plugging divided by impact energy vs. the projectile displacement, which was divided by the laminate thickness. In the all cases, it can be seen that there is a linear relationship between the energy absorbed by shear plugging and the displacement. The slopes of curves become steeper with the laminate thickness, because this energy is directly proportional to thickness. This behaviour is related to the model used to estimate this energy, as can be seen in Eq. (4).

For the impact energies and the thicknesses considered, the results show that the energy absorbed by shear plugging is a mechanism that does not appear from the beginning of the impact phenomenon, as can be seen in Fig. 6 for impact energy ( $77 \mathrm{~J})$. This

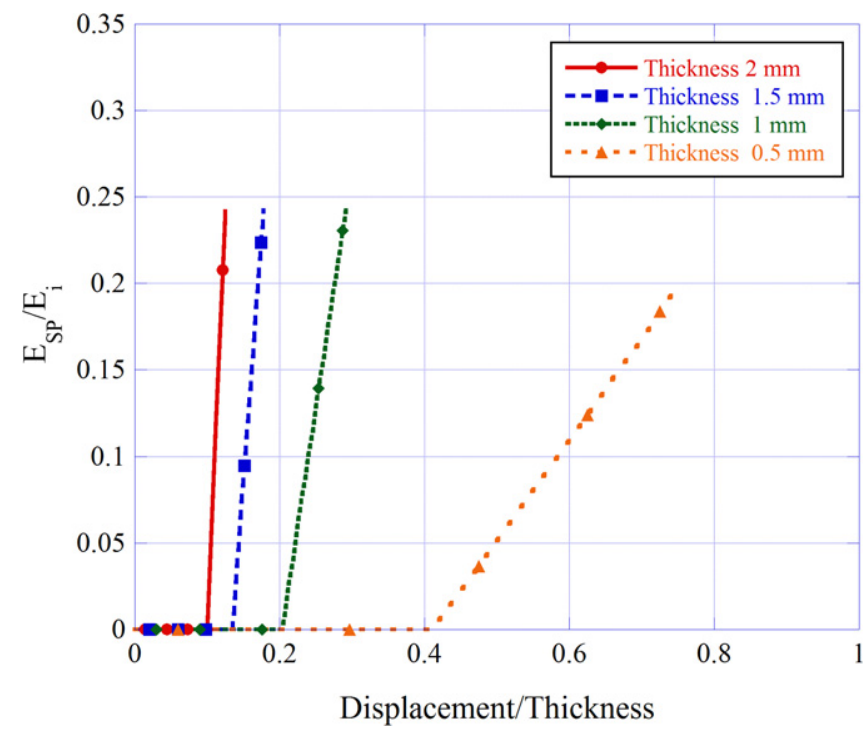

Fig. 7. Energy absorbed by shear plugging vs. displacement for AS4/8552 woven laminate at impact energy of $0.77 \mathrm{~J}$.

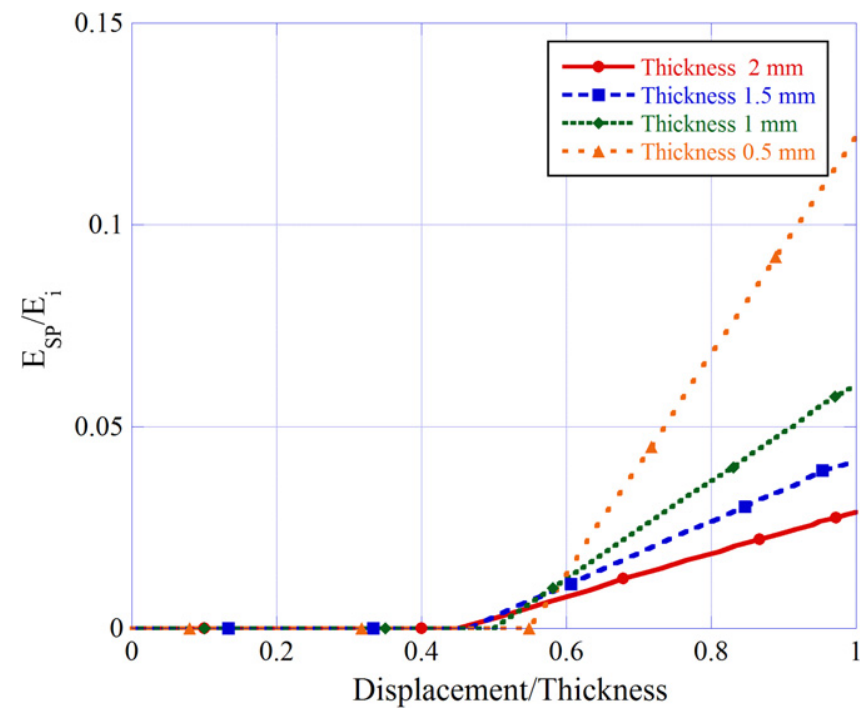

Fig. 8. Energy absorbed by shear plugging vs. displacement for AS4/8552 woven laminate at the perforation-threshold energy.

mechanism should appear only when the shear stress due to impact exceeds shear plugging strength.

For impact energy of $0.77 \mathrm{~J}$ (Fig. 7), the beginning of the energy absorption by shear plugging occurs at the same displacement, however, in percentage of the thickness decreases with the increase of thickness.

The phenomenon described above was not observed for impact energy equal to perforation-threshold energy (Fig. 8), because this energy differs for each thickness. Therefore, in percentage, this mechanism begins at the same value for all thicknesses.

For higher impact energy ( $77 \mathrm{~J}$ ), this was observed in behaviour similar to the impact energy below the perforation threshold (Fig. 9).

The main difference between this result and the previous one is that in this case for the thinner thicknesses the plug did not form, because these laminates behave somewhat like a membrane, as can be seen for an impact energy (77 J) in Figs. 5 and 6 . 


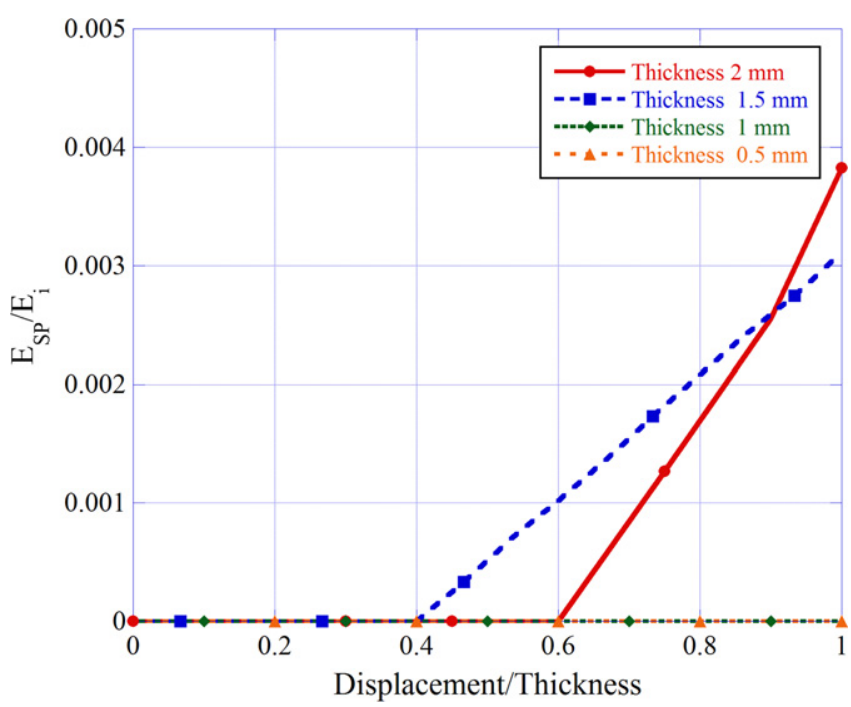

Fig. 9. Energy absorbed by shear plugging vs. displacement for AS4/8552 woven laminate at impact energy of $77 \mathrm{~J}$.

\section{Conclusions}

An analytical model was developed to analyse the impact behaviour of thin CFRP woven laminates, with thickness up to $2 \mathrm{~mm}$. The model was validated by experimental tests on a woven AS4/8552 laminate subjected to impact velocities of up to $560 \mathrm{~m} / \mathrm{s}$. The projectile residual velocities were also compared with those predicted by a numerical model. Good agreement was found in both cases. The main objective of this work was to evaluate the influence of the formation of a shear plug in the absorption of the energy of the projectile.

In thin CFRP woven laminates, between 1 and $2 \mathrm{~mm}$ thick, the shear plugging should be considered to be an energy-absorption mechanism. If this mechanism is not considered in the model, a difference of $30 \%$ results in the estimation of the energy absorbed by the laminate.

For impact energies that cause perforation, the main energyabsorption mechanism is the energy converted into laminate acceleration. For impact energies below the threshold energy, the main energy absorption is the elastic deformation of fibres. For a laminate with a thickness equal to $2 \mathrm{~mm}$, the second main mechanism is shear plugging. Even for impact energies slightly over the threshold, this latter mechanism could be the main mechanism. The energy absorbed by shear plugging tends asymptotically to a low value when the impact energy increases. This value rises when thickness is greater. The importance of this latter mechanism increases with thickness. Below $1.5 \mathrm{~mm}$ in thickness, and at high impact energies, the energy absorbed due to shear plugging is negligible. Nevertheless, for impact energies below and at the perforation-energy threshold, this mechanism needs to be taken into account, even for a thickness equal to $0.5 \mathrm{~mm}$.

The energy absorbed due to fibre failure is less relevant than in glass-reinforced laminates, due to the fragility of carbon fibres. The energy absorbed by the other mechanisms is negligible at high impact energies.

\section{Acknowledgement}

The authors are indebted to the Spanish Comision Interministerial de Ciencia y Tecnología (Project TRA2007-0440-001) for the financial support of this work.

\section{References}

[1] Cantwell WJ, Morton J. Impact perforation of carbon fiber reinforced plastic. Compos Sci Technol 1990;38:119-41.

[2] Abrate S. Impact on laminated composites: recent advances. Appl Mech Rev 1994;47(11):517-44.

[3] Ben-Dor G, Dubinsky A, Elperin T. Ballistic impact: recent advances in analytical modeling of plate perforation dynamic - a review. Appl Mech Rev 2005;58:355-69.

[4] Gower HL, Cronin DS, Plumtree A. Ballistic impact response of laminated composite panels. Int J Impact Eng 2008;35:1000-8.

[5] Ben-Dor G, Dubinsky A, Elperin T. An engineering approach to shape optimization of impactors against fiber-reinforced plastic laminates. Compos Part B: Eng 2009;40:181-8.

[6] Wu QG, Wen HM, Qin Y, Xin SH. Perforation of FRP laminates under by flatnosed projectiles. Compos Part B: Eng 2012;43:221-7.

[7] García-Castillo SK, Sánchez-Sáez S, López-Puente J, Barbero E, Navarro C. Impact behaviour of preloaded glass/polyester woven plates. Compos Sci Technol 2009;69:711-7.

[8] Naik NK, Shrirao P, Reddy BCK. Ballistic impact behaviour of woven fabric composites: formulation. Int J Impact Eng 2006;32:1521-52.

[9] Ulven C, Vaidya UK, Hosur MV. Effect of projectile shape during ballistic perforation of VARTM carbon/epoxy composite panels. Compos Struct 2003;61:143-50.

[10] García-Castillo SK, Sánchez-Sáez, Barbero E. Nondimensional analysis of ballistic impact on thin woven laminates plates. Int J Impact Eng 2012;39:8-15

[11] Morye SS, Hine PJ, Duckett RA, Carr DJ, Ward IM. Modelling of the energy absorption by polymer composites upon ballistic impact. Compos Sci Technol 2000;60:2631-42.

[12] Wen HM, Reddy TY, Reid SR, Soden PD. Indentation, penetration and perforation of composite laminate and sandwich panels under quasi-static and projectile loading. Key Eng Mater 1998;141-143:501-52.

[13] Mines RAW, Roach AM, Jones N. High velocity perforation behaviour of polymer composite laminates. Int J Impact Eng 1999;22:561-88.

[14] López-Puente J, Zaera R, Navarro C. An analytical model for high velocity impacts on thin CFRPs woven laminated plates. Int J Solids Struct 2007;44:2837-51.

[15] Lee SWR, Sun CT. Dynamic penetration of graphite/epoxy laminates by a blunt ended projectile. Comput Sci Technol 1993;49:369-80.

[16] Buitrago BL. Comportamiento de estructuras de material compuesto sometidas a cargas impulsivas. Ph.D. thesis; 2012. [in spanish].

[17] Tanabe Y, Aoki M, Fujii K, Kasano H, Yasuda E. Fracture behavior of CFRPs impacted by relatively high-velocity steel sphere. Int J Impact Eng 2003;28(6):627-42.

[18] Hazell PJ, Appleby-Thomas G. A study on the energy dissipation of several different CFRP-based targets completely penetrated by high velocity projectile. Compos Struct 2009;91:103-9.

[19] Goldsmith W, Dharan CKH, Chang H. Quasi-static and ballistic perforation of carbon fiber laminates. Int J Solids Struct 1995;32(1):89-103.

[20] Naik NK, Shrirao P. Composite structures under ballistic impact. Compos Struct 2004;66:579-90.

[21] Hosur MV, Vaidya UK, Ulven C, Jeelani. Performance of stitched/unstitched woven carbon/epoxy composites under high velocity impact loading. Compos Struct 2004:64:455-66.

[22] Pandya KS, Dharmane L, Pothnis JR, Ravikumar G, Naik NK. Stress wave attenuation in composites during ballistic impact. Polym Test 2012;31:261-6.

[23] García-Castillo SK, Buitrago BL, Barbero E. Behavior of sandwich structures and spaced plates subjected to high-velocity impact. Polym Compos 2011;2:290-6

[24] Naik NK, Shrirao P, Reddy BCK. Ballistic impact behavior of woven fabric composites: parametric studies. Mater Sci Eng A - Struct Mater Prop Microstruct Process 2005;412:104-16.

[25] García-Castillo SK, Sánchez-Sáez S, Santiuste C, Navarro C, Barbero Perforation of composite laminate subjected to dynamic loads. In: Abrate S, Castanié B, Yapa DSY, editors. Dynamic failure of composite and sandwich structures. Springer. ISBN: 978-94-007-5328-0. 2013

[26] MIL-STD-662F Standard. V50 Ballistic test for armor. Department of Defense Test Method Standard.

[27] Lambert JP, Jonas GH. Towards standardization in terminal ballistics testing: velocity representation. Army Ballistic Research. 1976 Rep. BRL-R-1852, Aberdyn, Maryland, USA.

[28] Kasano H. Impact perforation of orthotropic and quasi-isotropic CFRP laminates by a steel ball projectile. Adv Compos Mater 2001;10(4):309-18.

[29] Hashin Z, Rotem A. A fatigue failure criterion for fiber reinforced materials. Compos Mater 1973;7:448-64. 